\title{
Pheochromocytomas and paragangliomas in children: Data from the Italian Cooperative Study (TREP)
}

\section{Calogero Virgone ${ }^{1}$ (D) | Marina Andreetta ${ }^{1}$ | Stefano Avanzini ${ }^{2}$ | Stefano Chiaravalli ${ }^{3}$ \\ Maria Debora De Pasquale $^{4}$ | Alessandro Crocoli ${ }^{5}$ (D) | Alessandro Inserra ${ }^{5}$ (D) \\ Paolo D'Angelo6 (iD | Rita Alaggio7 | Giuseppe Opocher ${ }^{8,9}$ | Giovanni Cecchetto ${ }^{1}$ | \\ Andrea Ferrari $^{3}$ (D) | Gianni Bisogno ${ }^{10}$ (D) | Patrizia Dall'Igna ${ }^{1}$}

${ }^{1}$ Pediatric Surgery Unit, Department of Women's and Children's Health, University Hospital of Padua, Padua, Italy
${ }^{2}$ Department of Pediatric Surgery, Giannina Gaslini Children's Hospital, Genoa, Italy
${ }^{3}$ Department of Hematology/Oncology, IRCCS Istituto Nazionale dei Tumori, Milan, Italy
${ }^{4}$ Department of Oncohematology, Bambino Gesù Children's Hospital, IRCCS, Rome, Italy
${ }^{5}$ Department of Pediatric Surgery, Bambino Gesù Children's Hospital, IRCCS, Rome, Italy
${ }^{6}$ Hematology/Oncology Unit, ARNAS Civico Di Cristina e Benfratelli, Palermo, Italy
${ }^{7}$ Department of Pathology, Bambino Gesù Children's Hospital, IRCCS, Rome, Italy
${ }^{8}$ Scientific Direction, Veneto Institute of Oncology IRCCS, Padua, Italy
${ }^{9}$ Department of Medicine, DIMED, University of Padua, Padua, Italy
${ }^{10}$ Hematology/Oncology Unit, Department of Women's and Children's Health, University-Hospital of Padua, Padua, Italy

Correspondence

Calogero Virgone, MD, PhD, Pediatric Surgery Unit, Department of Women's and Children's Health, University Hospital of Padua, Via Giustiniani 3, 35128 Padua, Italy.

Email: calogero.virgone@unipd.it

Part of these data have been discussed as an oral presentation at the 48th Annual Congress of the International Society of Pediatric Oncology (SIOP) held in Dublin (Ireland) in 2016 (Pheochromocytomas and Paragangliomas in Children: Data from the Italian Multiinstitutional Study (TREP project) on Rare Tumors in Childhood (2000-2014), Pediatric Blood \& Cancer 63, S46-S46).

\section{Funding information}

The TREP project is partially supported by a grant from "Fondazione Giovanni Celeghin ONLUS," Padova.

\begin{abstract}
Background: Pheochromocytomas (PCs) are neuroendocrine tumors arising from the chromaffin cells of the adrenal gland, and paragangliomas (PGLs) are their extra-adrenal counterparts arising from ganglia along the sympathetic/parasympathetic chain. Surgery is the cornerstone of treatment. A sporatic or inherited germline mutation is commonly associated.

Materials and methods: Among over 1000 patients registered into the Tumori Rari in Età Pediatrica-rare tumors in pediatric age project-from 2000 to 2019, 50 were affected by PC/PGL. All clinical and therapeutic data were evaluated.

Results: Twenty-eight patients had PC and 22 had PGL. Age at diagnosis ranged between 5 and 17 years. Thirty-five patients had symptoms related to catecholamine hypersecretion; in 7 of 50 patients, diagnosis was incidental or done during assessment of a familial syndrome. In all cases, conventional imaging was effective to assess the presence of a tumor. In addition, 18 of 38 functional imaging studies were positive (61\%). Forty-eight patients were eligible for surgery: a complete resection was more frequently achieved in PC than in PGL (26/28 vs $11 / 22)$. All relapses were treated with surgery alone, surgery plus medical treatment, or chemotherapy alone; one PC with metastasis at diagnosis received radiotherapy only. Forty-four patients were in the first, second, or third complete remission (10/50 recurred; $8 / 10$ carried a germline mutation). Five of 50 patients were alive with disease. One patient died of disease.
\end{abstract}

Abbreviations: ${ }^{18}$ F-DOPA, fluorine-18-L-dihydroxyphenylalanine; ${ }^{18}$ F-FDG, fluorine-18-fluorodeoxyglucose; ${ }^{123}$ I-MIBG, ${ }^{123}$ iodium-metaiodobenzylguanidine; ${ }^{177}$ Lu-DOTATATE, lutetium-177-DOTA ${ }^{0}$-Tyr ${ }^{3}$-octreotate; CT, computed tomography; EFS, event-free survival; Max, MYC-associated factor X; MRI, magnetic resonance imaging; NF1, neurofibromin 1; OS, overall survival; PC, pheochromocytoma; PET/CT, positron emission tomography/computed tomography; PGL, paraganglioma; Ret, rearranged during transfection; SDHA, succinate dehydrogenase complex flavoprotein subunit A; SDHAF2, succinate dehydrogenase complex assembly factor 2; SDHB, succinate dehydrogenase complex iron sulfur subunit B; SDHC, succinate dehydrogenase complex subunit C; SDHD, succinate dehydrogenase complex subunit D; TMEM127, transmembrane protein 127; TREP, Tumori Rari in Età Pediatrica-rare tumors in pediatric age; VHL, von Hippel-Lindau. 
Conclusions: Surgery can be curative in most tumors but it may not be always effective in removing PGLs. Severe postsurgical sequelae may affect these patients. Genetic tests should always be considered in individuals affected, and genetic counseling should be offered to their families.

KEYWORDS

children, paraganglioma, pheochromocytoma, rare cancer

\section{1 | INTRODUCTION}

Pheochromocytomas and paragangliomas (PCs/PGLs) are rare catecholamine-producing tumors that may arise, respectively, from the adrenal medulla or extra-adrenal ganglia along the sympathetic/parasympathetic chains (chromaffin or nonchromaffin origin). Their incidence varies from 0.2-0.3 to 2 cases per million children per year. ${ }^{1,2}$ Symptoms are related to the catecholamine hypersecretion, and diagnosis is based on the determination of plasma and urinary metanephrines (sometimes catecholamines), radiological characterization, and functional imaging tests. ${ }^{3}$ Although in most cases they are sporadic, they may be also part of a more complex hereditary syndrome. Actually PC/PGL are more commonly associated with an inherited mutation than any other cancer type, and these mutations normally involve genes such as von Hippel-Lindau (VHL), rearranged during transfection (Ret), neurofibromin 1 (NF1), SDH-x, and MYC-associated factor $X(M A X) .{ }^{4}$ Over one third of patients with paraganglial tumors carry germline mutations in one of the ten susceptibility genes: VHL, Ret, NF1, succinate dehydrogenase complex assembly factor 2 (SDHAF2), succinate dehydrogenase complex flavoprotein subunit $A(S D H A)$, succinate dehydrogenase complex iron sulfur subunit $B(S D H B)$, succinate dehydrogenase complex subunit C (SDHC), succinate dehydrogenase complex subunit $D(S D H D), M A X$, and transmembrane protein 127 (TMEM127). ${ }^{5-11}$ Surgery remains the main curative treatment. ${ }^{12}$ Due to the rarity of these tumors in children, their genetic and biologic characteristics are still not well defined. On the other hand, diagnostic and therapeutic guidelines do exist for familial forms and they may be of help during screening and surveillance of this subset of PC/PGL. ${ }^{13}$

The purpose of this study is to analyze the clinical findings, treatment, and outcome observed in pediatric patients (age $<18$ ) with PC/PGL, registered in our National Study on Rare tumors in children (Tumori Rari in Età Pediatrica-Rare Tumors in Pediatric Age (TREP) project), in order to evaluate the efficacy of our clinical, diagnostic, and therapeutic approach, and to offer a contribution to literature on these tumors.

\section{I MATERIALS AND METHODS}

The TREP project, launched and approved by the local ethics committee in 2000, represents the first Italian multi-institutional network on very rare tumors in children and adolescents (age $<18$ ). The histotypes registered are those with an incidence of less than two cases per 1 million children, and not treated in current national or interna- tional protocols. ${ }^{14,15}$ In addition to patient enrolment and registration, the TREP project provides diagnostic and therapeutic recommendations (according to the recent literature data), helping physicians in approaching these rare neoplasms.

The records of 50 evaluable patients with PC/PGL enrolled in the TREP project between January 2000 and January 2019 were reviewed. Data regarding clinical presentation, diagnostic workup, treatment, outcome, and follow-up were obtained prospectively through special printed forms, and the records of all the cases were centrally reviewed for this report. Missing data were obtained from the physicians in charge from all Centers of Pediatric Oncology and Surgery in Italy. Statistical analyses were performed using IBM SPSS Statistics ${ }^{\circledR}$ version 25 . All the patients, or their guardians, gave informed consent for their involvement in the TREP study.

\section{RESULTS}

The clinical features are summarized in Tables 1 and 2. Mean age at diagnosis was 12 years for both groups (range 5-17 years).

\section{1 | Clinical findings}

\subsection{1 | Pheochromocytomas}

Twenty-eight patients had PC: three of them were bilateral at diagnosis. All patients, except two, underwent genetic assessment and 15 had a germline mutation: 10 patients were affected by VHL syndrome, three by hereditary PGL/PC type 4 (SDHB), one by neurofibromatosis type 1 (NF1), and one by MEN 2A (ret). All patients with bilateral tumors at diagnosis were affected by $\mathrm{VHL}$ syndrome.

In 20 cases, the clinical presentation included symptoms related to catecholamine hypersecretion (all with altered levels of urinary metanephrines): hypertension or hypertensive crises were the first sign in 19 cases, typically associated with diaphoresis and headache. Other symptoms included weight loss, fever, abdominal pain, tachycardia, asthenia, and seizures. Three patients had signs of hypertensive cardiomyopathy, and one presented a systemic hypertensive disease that involved heart, kidneys, and retina. In three patients, the tumor was diagnosed incidentally: in two, during assessment for a known familial syndrome, and in one after an ultrasound scan performed because of abdominal pain.

Twenty-four of 28 patients had available data on urinary or plasmatic markers: 22 (78.8\%) presented elevated urinary or plasmatic catecholamines and/or methanephrines; in two patients, markers were not altered. 
TAB LE 1 Clinical features of 28 patients with PC

\begin{tabular}{|c|c|}
\hline Median age (months) & $\begin{array}{l}\text { 150.5 (Mean } \\
146.6)\end{array}$ \\
\hline \multicolumn{2}{|l|}{ Sex } \\
\hline Males & $19(67.8 \%)$ \\
\hline Females & $9(32.1 \%)$ \\
\hline \multicolumn{2}{|l|}{ Germline mutation } \\
\hline Positive & $15(53.6 \%)$ \\
\hline Negative & $11(39.3 \%)$ \\
\hline Not tested & $2(7.1 \%)$ \\
\hline \multicolumn{2}{|l|}{ Surgical approach } \\
\hline Open & $18(64.3 \%)$ \\
\hline VLS & $10(35.7 \%)$ \\
\hline \multicolumn{2}{|l|}{ Resection } \\
\hline Complete & $26(92.9 \%)$ \\
\hline With residuals & $2(7.1 \%)$ \\
\hline \multicolumn{2}{|l|}{ Symptoms } \\
\hline Catecholaminergic & $20(71.4 \%)$ \\
\hline Incidental diagnosis or screening & $3(10.7 \%)$ \\
\hline Abdominal pain & $1(3.5 \%)$ \\
\hline Unknown & $2(7.1 \%)$ \\
\hline \multicolumn{2}{|l|}{ Side at diagnosis } \\
\hline Right & $12(42.9 \%)$ \\
\hline Left & $13(46.4 \%)$ \\
\hline Bilateral & $3(10.7 \%)$ \\
\hline \multicolumn{2}{|l|}{ Size } \\
\hline$<5 \mathrm{~cm}$ & $14(50 \%)$ \\
\hline$\geq 5 \mathrm{~cm}$ & $12(42.9 \%)$ \\
\hline Unknown & $2(7.1 \%)$ \\
\hline \multicolumn{2}{|l|}{ Secreting status } \\
\hline Secreting & $22(78.6 \%)$ \\
\hline Not secreting & $2(7.1 \%)$ \\
\hline Unknown & $4(14.3 \%)$ \\
\hline \multicolumn{2}{|l|}{ Conventional imaging } \\
\hline $\mathrm{CT}$ & $15(53.6 \%)$ \\
\hline MRI & $13(46.4 \%)$ \\
\hline Unknown & $2(7.1 \%)$ \\
\hline \multicolumn{2}{|l|}{ Functional imaging } \\
\hline 123/-MIBG scintigraphy & $11(7)^{\mathrm{a}}$ \\
\hline $\begin{array}{l}\mathrm{PET} / \mathrm{CT}\left({ }^{18} \mathrm{~F}-\mathrm{DOPA}, 1^{18} \mathrm{~F}-\mathrm{FDG}, 1\right. \\
{ }^{111} \text { In-Pentreotide) }\end{array}$ & $3(1)^{a}$ \\
\hline \multirow[t]{2}{*}{ Follow-up (months) } & Median 54 \\
\hline & Mean 58.9 \\
\hline
\end{tabular}

Abbreviations: ${ }^{123}$ I-MIBG, ${ }^{123}$ iodium-metaiodobenzylguanidine; MRI, magnetic resonance imaging.

${ }^{a}$ The number of altered functional imaging are in parentheses.
TAB LE 2 Clinical features of 22 patients with PGL

\begin{tabular}{|c|c|}
\hline Median age (months) & $\begin{array}{l}143.5 \text { (Mean } \\
148.1)\end{array}$ \\
\hline \multicolumn{2}{|l|}{ Sex } \\
\hline Males & $14(63.6 \%)$ \\
\hline Females & $8(36.4 \%)$ \\
\hline \multicolumn{2}{|l|}{ Germline mutation } \\
\hline Positive & $10(45.5 \%)$ \\
\hline Negative & $7(31.8 \%)$ \\
\hline Not tested & $5(22.7 \%)$ \\
\hline \multicolumn{2}{|l|}{ Resection } \\
\hline Complete & $10(45.6 \%)$ \\
\hline With residuals & $12(54.4 \%)$ \\
\hline \multicolumn{2}{|l|}{ Symptoms } \\
\hline Catecholaminergic & $15(68.1 \%)$ \\
\hline Mass effect & $2(9.1 \%)$ \\
\hline Incidental diagnosis & $4(18.2 \%)$ \\
\hline Abdominal pain & $5(22.7 \%)$ \\
\hline Unknown & $1(4.5 \%)$ \\
\hline \multicolumn{2}{|l|}{ Site } \\
\hline Abdomen & $16(72.2 \%)$ \\
\hline Head and neck & $2(9.1 \%)$ \\
\hline Pelvis & $3(13.6 \%)$ \\
\hline Mediastinum & $1(4.5 \%)$ \\
\hline \multicolumn{2}{|l|}{ Size } \\
\hline$<5 \mathrm{~cm}$ & $12(54.4 \%)$ \\
\hline$>5 \mathrm{~cm}$ & $10(45.6 \%)$ \\
\hline \multicolumn{2}{|l|}{ Secreting status } \\
\hline Secreting & 9 (41\%) \\
\hline Not secreting & $12(54.4 \%)$ \\
\hline Unknown & $1(4.5 \%)$ \\
\hline \multicolumn{2}{|l|}{ Conventional imaging } \\
\hline CT & $19(86.4 \%)$ \\
\hline MRI & $11(50 \%)$ \\
\hline Unknown & $1(4.5 \%)$ \\
\hline \multicolumn{2}{|l|}{ Functional imaging } \\
\hline${ }^{123}$ I-MIBG scintigraphy & $13(2)^{\mathrm{a}}$ \\
\hline $\begin{array}{l}\text { PET/CT (2 }{ }^{18} \mathrm{~F} \text {-FDG, } 2{ }^{67} \mathrm{Ga} \text {-DOTATOC, } \\
\quad{ }^{18} \mathrm{~F} \text {-DOPA) }\end{array}$ & $8(8)^{a}$ \\
\hline${ }^{99}$ Tc scintigraphy & $3(0)^{a}$ \\
\hline \multirow[t]{2}{*}{ Follow-up (months) } & Median 55 \\
\hline & (Mean 61.3) \\
\hline
\end{tabular}

Abbreviations: ${ }^{67} \mathrm{Ga}$-DOTATOC, ${ }^{67} \mathrm{Ga}$-DOTA-Phe1-Tyr3-octreotide; ${ }^{123} \mathrm{I}$ MIBG, ${ }^{123}$ iodium-metaiodobenzylguanidine; MRI, magnetic resonance imaging.

${ }^{a}$ The number of altered functional imaging are in parentheses. 
In all cases, computed tomography (CT) scan or magnetic resonance imaging (MRI) was useful to detect or assess the tumors. ${ }^{123}$ lodiummetaiodobenzylguanidine (123/-MIBG) scintiscan was additionally performed in 11 cases and in 7 was altered. One patient underwent fluorine-18-L-dihydroxyphenylalanine ( ${ }^{18} \mathrm{~F}$-DOPA) positron emission tomography/computed tomography (PET/CT) scan, which confirmed the diagnosis and revealed an asymptomatic bone metastasis in the thoracic spine.

\subsection{2 | Paragangliomas}

Twenty-two patients had PGL. Ten of 22 children had a germline mutation: two children had VHL syndrome, six had hereditary PGL/PC type 1 syndrome (SDHB), and two had hereditary PGL/PC type 4 syndrome $(S D H D)$. The genetic tests were not performed in five patients (in one case due to parents' opposition). In 15 cases the main symptom was hypertension, associated with headache, diaphoresis, fever, dyspnea, gastrointestinal, and visus disorders. One patient also had chest pain and 2 of 13 presented with acute heart failure due to hypertensive cardiomyopathy. In three patients, the tumor was detected incidentally and in one of them during assessment for a familial syndrome. Two patients with head-and-neck PGL had symptoms related to tumor mass effect (tinnitus, hypoacusia, earache, palpable mass in the temporal region); one patient had nonspecific abdominal pain, and one had pelvic PGL, metrorrhagia.

Data on urinary and plasmatic markers were available in 21 of 22 children, but only 9 (41\%) had altered catecholamines and/or methanephrines levels.

A scintiscan with ${ }^{123}$ I-MIBG was performed in 13 of 22 patients, and was altered in two cases only, whereas PET/CT scan, performed in eight patients (two fluorine-18-fluorodeoxyglucose ( ${ }^{18} \mathrm{~F}-\mathrm{FDG}$ ), four ${ }^{18} \mathrm{~F}$-DOPA, two ${ }^{67} \mathrm{Ga}$-DOTA-Phe1-Tyr3-octreotide), was altered in all cases.

\section{2 | Treatment}

All patients eligible for surgery and with secreting tumors or signs of hypertensive disease were pharmacologically treated with alphaadrenergic antagonists (doxazosin or prazosin), which were started at least 15 days before the operation.

\subsection{1 | Pheochromocytomas}

All patients with PC (28) were eligible for surgery: all the patients with unilateral mass (25) underwent total adrenalectomy (23) or partial adrenalectomy ( 2 cases). A bilateral adrenalectomy was performed in one of the three patients with bilateral tumors, and the subsequent adrenal failure is currently treated with chronic glucocorticoid replacement therapy. In the other two patients, a total adrenalectomy on one side, and a partial adrenalectomy on the other side were performed with a mini-invasive procedure (laparoscopy): nevertheless, one of the two patients developed adrenal failure after surgery. A mini-invasive approach was utilized overall in 10 patients and in 2 of them conversion to open surgery was necessary. After surgery, one patient received external radiotherapy on her spinal metastasis.
The mean diameter of the mass was $5.3 \mathrm{~cm}$ (range 1-11 cm); resections were complete (RO) in all cases but two, in which histological examination showed residual disease at the margins of resection.

Intraoperative complications occurred in four cases (14\%), three of them during laparoscopy: two patients had hypertensive crisis due to mass manipulation, one patient had severe hypotension after mass removal, and another patient required conversion to laparotomy because of a severe bleeding. Postoperative complications were observed in three cases (11\%) and were represented by acute pulmonary edema, persisting hypertension subsequent to atrophic kidney (ipsilateral to the mass) and severe bleeding that needed reoperation (two grade II and one grade IIIb, according modified Clavien-Dindo Classification).

\subsubsection{Paragangliomas}

Most of the tumors were retroperitoneal; one was localized in the mediastinum and two in head/neck. Twenty of 22 patients were eligible for surgery: one patient with a paravertebral mass underwent also angiographic embolization before surgery, in order to reduce the mass volume.

In two cases, surgery was not feasible. In one case, the patient with a locally invasive PGL of the middle cranial fossa underwent biopsy and angiographic embolization of the tumor and received chemotherapy (one cycle with ifosfamide, vincristine, and actinomycin D, and four cycles with doxorubicine, cisplatin, and etoposide), before opting out. The other patient, with an invasive PGL of the posterior mediastinum, underwent biopsy and received chemotherapy (nine cycles comprising vincristine, carboplatin, etopside, adriamycin, and ifosfamide), radiotherapy, sandostatin, and an autologous stem cell transplant. In both cases it was difficult to assess the response to chemotherapy, since it was administered in a multimodal scenario; however both tumors showed a partial response (tumor size reduction $>1 / 3$ and $>2 / 3$, respectively).

The mean diameter was $4.9 \mathrm{~cm}$ (range 1.7-10.4 cm). In 11 cases a complete resection was not achievable, and residual disease was left on the resection margins (R1/R2).

Surgical complications were observed in 9 of 20 patients. Intraoperative complications in five $(25 \%)$ were hypertensive crisis due to mass manipulation (two cases), severe bleeding requiring transfusion (two cases), and severe hypotension (one case). Postoperative complications occurred in four (20\%) patients (one each for grade I, grade II, grade IIIb, and grade IVa): hypotensive crisis; bradycardia and cardiac arrest; pancreatic fistula; severe first bite syndrome associated to facial nerve paralysis, hear loss, and ClaudeBernard-Horner syndrome; and iatrogenic ischemia of the kidney, which required an aortorenal bypass.

\section{3 | Relapses, metachronous tumors, and outcome}

\subsubsection{Pheochromocytomas (see Table $\mathbf{3}$ for details)}

Relapses and metachronous tumors occurred in 6 of 28 patients after a mean period of 59 months (range 3-132 months); all had a 
TAB LE 3 Clinical features of patients with relapse or metachronous tumors

\begin{tabular}{|c|c|c|c|c|c|c|c|c|}
\hline Patient & $\begin{array}{l}\text { Age at } \\
\text { diagnosis (in } \\
\text { months) }\end{array}$ & Sex & Syndrome & Site & First treatment & $\begin{array}{l}\text { Re or } \mathrm{mT} \text { (months } \\
\text { from the previous } \\
\text { treatment) }\end{array}$ & $\begin{array}{l}\text { Treatment of the } \\
\text { relapse }\end{array}$ & $\begin{array}{l}\text { Outcome } \\
\text { (FU } \\
\text { months) }\end{array}$ \\
\hline PC1 & 215 & M & MEN 2A & Left adrenal gland & $\begin{array}{l}\text { Left } \\
\text { adrenalectomy } \\
\text { (MIS) }\end{array}$ & $\begin{array}{l}\text { PC on the right } \\
\text { adrenal gland } \\
\text { (120) }\end{array}$ & $\begin{array}{l}\text { Adrenal-sparing } \\
\text { tumorectomy }\end{array}$ & $\begin{array}{l}\text { 2nd CR } \\
\text { (48) }\end{array}$ \\
\hline PC2 & 129 & $\mathrm{~F}$ & $\begin{array}{l}\text { Familial } \\
\text { paraganglioma } \\
\text { type } 4 \text { (SDHB) }\end{array}$ & Left adrenal gland & $\begin{array}{l}\text { Left } \\
\text { adrenalectomy }\end{array}$ & $\begin{array}{l}\text { Liver metastases } \\
\text { (96) }\end{array}$ & $\begin{array}{l}\text { Radiometabolic } \\
\text { therapy (ongoing } \\
\text { with lutetium-177- } \\
\text { DOTA }{ }^{0} \text {-Tyr }{ }^{3} \text { - } \\
\text { octreotate) }\end{array}$ & AWD (8) \\
\hline PC3 & 77 & M & VHL & $\begin{array}{l}\text { Left adrenal gland } \\
+ \\
\text { interaortocaval } \\
\text { node }\end{array}$ & $\begin{array}{l}\text { Adrenal-sparing } \\
\text { tumorectomy }+ \\
\text { interaortocaval } \\
\text { node resection } \\
\text { (MIS) }\end{array}$ & $\begin{array}{l}\text { 1. Interaortocaval } \\
\text { nodes (3) } \\
\text { 2. Right adrenal } \\
\text { gland (9) } \\
\text { 3. Right adrenal } \\
\text { gland; left } \\
\text { pararenal } \\
\text { nodule + lung } \\
\text { metastases (24) } \\
\text { 4. Diffuse } \\
\text { metastatic } \\
\text { relapse: lung, } \\
\text { liver, bones and } \\
\text { iliac nodes (12) }\end{array}$ & $\begin{array}{l}\text { 1. Interaortocaval } \\
\text { lymphadenectomy } \\
\text { 2. Adrenal-sparing } \\
\text { tumorectomy (MIS) } \\
\text { 3. Right } \\
\text { adrenalectomy and } \\
\text { left pararenal } \\
\text { nodule resection + } \\
\text { TM } \\
\text { 4. Radiometabolic } \\
\text { therapy (ongoing } \\
\text { with lutetium-177- } \\
\text { DOTA } \text { Tyr }^{3} \text { - } \\
\text { octreotate) }\end{array}$ & $\operatorname{AWD}(6)$ \\
\hline PC4 & 153 & M & VHL & $\begin{array}{l}\text { Right adrenal } \\
\text { gland }\end{array}$ & $\begin{array}{r}\text { Adrenal-sparing } \\
\text { tumorectomy }\end{array}$ & $\begin{array}{l}\text { 1. Right adrenal } \\
\text { gland (9) } \\
\text { 2. Left adrenal } \\
\text { gland and } \\
\text { interaortocaval } \\
\text { nodes (26) }\end{array}$ & $\begin{array}{l}\text { 1. Right } \\
\text { adrenalectomy } \\
\text { 2. Left } \\
\text { adrenalectomy + } \\
\text { interaortocaval } \\
\text { lymphadenectomy } \\
\text { + radiometabolic } \\
\text { therapy (MIBG) }\end{array}$ & $\begin{array}{c}3 r d C R \\
(84)\end{array}$ \\
\hline PC5 & 83 & $\mathrm{~F}$ & VHL & $\begin{array}{l}\text { Right adrenal } \\
\text { gland }\end{array}$ & $\begin{array}{l}\text { Right } \\
\text { adrenalectomy }\end{array}$ & $\begin{array}{l}\text { Left adrenal gland } \\
\text { (132) }\end{array}$ & Left adrenalectomy & $\begin{array}{l}\text { 2nd CR } \\
\text { (12) }\end{array}$ \\
\hline PGL3 & 130 & M & VHL & $\begin{array}{l}\text { Right retroperi- } \\
\text { toneum }\end{array}$ & Complete excision & $\begin{array}{l}\text { Bilateral adrenal } \\
\text { glands (48) }\end{array}$ & $\begin{array}{l}\text { Right adrenalectomy } \\
\text { and left } \\
\text { adrenal-sparing } \\
\text { tumorectomy }\end{array}$ & $\begin{array}{r}\text { 2nd CR } \\
\text { (lost) }\end{array}$ \\
\hline PGL4 & 144 & $f$ & None & Left pelvis & $\begin{array}{l}\text { Excision with } \\
\text { microscopic } \\
\text { residuals }\end{array}$ & Local relapse (40) & $\begin{array}{l}\text { Debulking + } \\
\text { chemotherapy } \\
\text { (ADM, VP-16 and } \\
\text { CDDP) }\end{array}$ & AWD (48) \\
\hline
\end{tabular}

Abbreviations: ADM; adriamicine; AWD, alive with disease; CBDCA; carboplatin; CDDP; cisplatin; CP, Cyclophosphamide; CR, complete remission; IFO, Ifosfamide; MIS, mini-invasive surgery; mT, metachronous tumors; PGL, paraganglioma; Re, relapses; SCT; stem cell transplant; TMZ, temozolamide; VCR, vincristine; VHL, von Hippel-Lindau; VP-16, etoposide; ${ }^{123}$ I-MIBG, ${ }^{123}$ iodium-metaiodobenzylguanidine.

familial syndrome (four had VHL syndrome, one had MEN 2A syndrome, and one had PGL/PC type 1 syndrome) and 3 of 6 patients had previously undergone laparoscopic surgery. Three patients (two with VHL syndrome and one with MEN 2A) who underwent unilateral adrenalectomy developed contralateral tumors: all were treated with surgery and in two cases a partial adrenalectomy was feasible. Two patients with $\mathrm{VHL}$ syndrome developed multiple local, contralateral, and distant relapses (nodes and paraganglia): one received multiple 
resections and ${ }^{123}$ I-MIBG metabolic therapy and reached a third complete remission; one, despite multiple surgeries to the contralateral adrenal gland, nodes, and paraganglial relapses, developed diffuse metastatic disease (liver, lung, bones, and distant nodes). Another patient developed liver metastases 8 years after the first surgery and is currently in the charge of an adult center. The latter two patients are currently receiving ongoing radiometabolic therapy based on lutetium-177-DOTA ${ }^{0}$-Tyr ${ }^{3}$-octreotate ( ${ }^{177}$ Lu-DOTATATE).

At the time of this report, all patients are alive, 26/28 in complete remission and two with disease (overall survival [OS] 100\%; event-free survival [EFS] 79\%): four of them are suffering from adrenocortical failure. Mean follow-up was 58.9 months (range: 2-156 months): four patients were lost to follow-up while in complete remission.

\subsection{2 | Paragangliomas (see Table 3 for details)}

Relapses occurred in four of 22 patients after a mean period of 52 months (range: 3-120 months): two of four occurred in patients who underwent incomplete tumor resection and only two of four had a germline mutation. One patient with $\mathrm{VHL}$ syndrome and a right pararenal PGL, who underwent complete tumor resection, developed ipsilateral recurrence and left paravertebral metastasis and required right adrenalectomy and partial left adrenalectomy. Two patients with locally invasive pelvic PGL developed multifocal recurrence: in one case, the relapse was treated with chemotherapy and the patient was alive with minimal stable disease; in the other case relapse was treated with neoadjuvant chemotherapy, surgery (with microscopic residuals), adjuvant chemotherapy followed by autologous stem cell transplantation, and demolitive surgery on the residual disease. The latter patient was able to achieve a second remission. One patient, affected by a completely resected retroperitoneal PGL, experienced diffuse bone metastases 10 years after surgery and he is being treated with a wait-andsee strategy at the time of this report. The patient with unresectable mediastinal PGL received further chemotherapy after mass growth, but died while receiving palliative care.

At the time of this report, 18 patients are alive in complete remission (3/18 lost at follow-up), but 2 with severe sequelae: 1 patient developed first bite syndrome and Claud-Bernard-Horner syndrome and 1 patient developed neurogenic bladder after mutilating surgery. Three patients are alive with stable disease (1/3 opted out) and one patient died of disease (OS 95\%; EFS 77\%). Mean follow-up was 61.3 months (range: 0-168 months).

\section{4 | Pathology}

Pheochromocytoma of the adrenal gland-scaled score (PASS) was available in the original pathology report in 14 of 28 patients with PC and in 8 of 22 patients with PGL. The score was reported to be $>4$ in four of 14 patients with PC and in five of eight patients with PGL. Among the patients with a malignant appearance at histology, only one patient with PGL (with familial PGL/PC type 4) experienced a recurrent disease, while the other two patients with PGL presented with a bone metastasis at diagnosis in one case (negative for germline mutation; in first CR) and a locally invasive tumor in the other case (opted out in alive with disease status and not tested). In the benign group, recurrent disease occurred in four patients with $P C$ (all with a germline mutation: two with VHL syndrome, one with MEN 2A syndrome, and one with familial PGL/PC type 4) and in one patient with PGL (with VHL syndrome).

\subsection{Statistical analysis}

EFS curves and cumulative risk curves (Figures 1 and 2) according Kaplan-Meier method were built and tested with log-rank (MantelCox): $P$ values of $<0.05$ were considered significant. Univariate analysis, performed by grouping PC and PGL together, showed no statistically significant difference in EFS for the presence of a germline mutation, the completeness of surgery, the sex of the patient, and the age at diagnosis.

\section{4 | DISCUSSION}

PC/PGL are rare tumors, however information on the exact incidence in children and adolescents is missing. This is particularly true for tumors affecting adolescents, mostly observed and treated in centers for adults. After the launch of the TREP project, Pastore et al. underlined a remarkable increase in the enrolment of patients between the ages of 0 and 14 years; however, the real incidence is difficult to determine without the involvement of the adult centers. ${ }^{14,15}$

A diagnosis of $\mathrm{PC} / \mathrm{PGL}$ is often not simple: for $\mathrm{PC}$, the differential diagnosis includes neuroblastoma, a more frequent tumor in children, and adrenocortical tumor, which is also very rare, but with different clinical characteristics. Thus, adrenal masses should be properly evaluated, with an accurate analysis of the clinical features and serum and urinary markers, and the proper selection of conventional and functional imaging. CT scan and MRI have been demonstrated to be equally useful to describe the radiological aspects of the tumor, the size, the involvement of vital structures, and possibly define a proper operative approach. In recent years, both ${ }^{18} \mathrm{~F}$-FDG and ${ }^{18} \mathrm{~F}$-DOPA $\mathrm{PET} / \mathrm{CT}$ have demonstrated to be the gold standard in providing a more accurate staging (123-131 I-MIBG is considered to perform equally well in localized cases), and additional information regarding metabolic activity and biologic aggressiveness of these tumors to possibly guide treatment choices. ${ }^{1,3,16}$

A complete preoperative workup should include genetic counseling because one third of patients with paraganglial tumors carry germline mutations in one of the susceptibility genes: RET, VHL, NF1, SDHAF2, SDHA, SDHB, SDHC, SDHD, TMEM127, and MAX. In our series, 43 of 50 patients were evaluated for a germline mutation, and in 25 cases $(>50 \%)$ tumors were associated with an inherited mutation. Among them, three tumors arose in patients who already had a diagnosis of an inherited mutation (two with PC, one with PGL). Most of the remaining patients were tested for VHL syndrome, familial PGL syndromes, and MEN syndromes: in 14 of them a diagnosis of a cancer-predisposing syndrome was possible, and it is remarkable how in 6 of them a positive familial history was also present. As previously reported, ${ }^{4,6,17}$ SDHB 
FIGURE 1 Cumulative risk of event occurrence (local or distant relapse, or metachronous tumor) comparing patients with or without a germline mutation or not tested
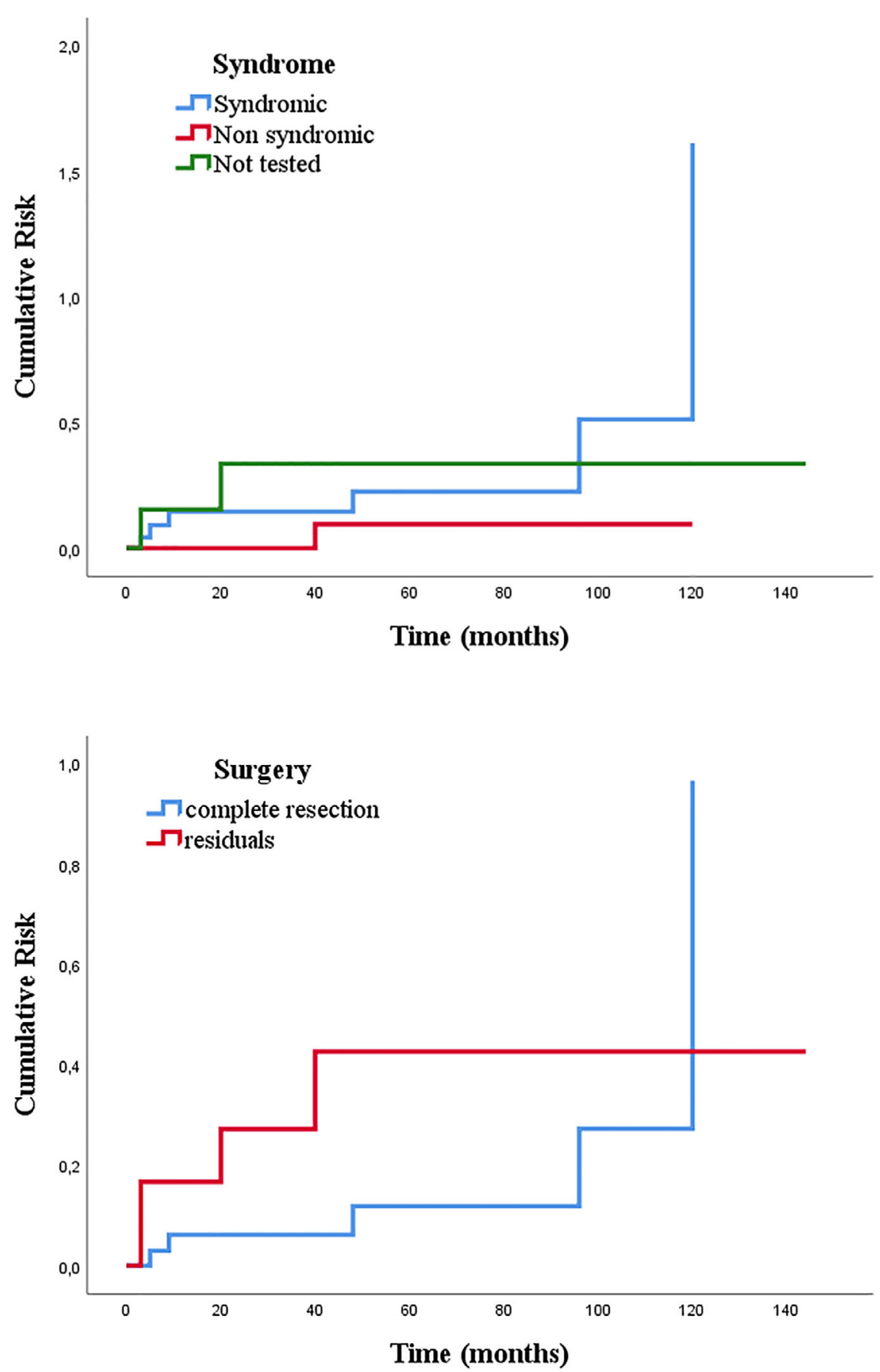

FIGURE 2 Cumulative risk of relapse (local or distant) comparing patients who received a complete excision and those with residuals after surgery resulted to be the most frequent mutated gene in patients affected by PGL, while VHL the most frequent in patients with PC.

The rate of tumors arising in syndromic patients is yet to be clearly defined: recently, some authors ${ }^{1,3}$ reported up to $80 \%$ of genetic mutations in their series, comparing them with lower proportions in previous reports (22-70\%). 2,5,18-20 The difference in the prevalence rate of germline mutations in the various series, including ours, may be due to a selection bias, ${ }^{1}$ which reflects the fact that children with a positive familial history of FC/PGL may sometimes be treated outside pediatric centers. As one may deduce, a reliable estimate of the prevalence rate of syndromic PC/PGL on the total amount of pediatric PC/PGL cases could be definitely ruled out only by international prospective studies or tumor registries. Of course, all authors agree to recommend that all patients presenting with a PC/PGL, with or without a positive family history, should undergo genetic testing. ${ }^{1,4}$

The surgical approach for a PC should be planned according to the secretion status of the tumor, the presence of bilateral lesions, and surgeon's experience. Special attention moreover should be given to children with an inherited syndrome who could benefit of a cortical-sparing surgery since a metachronous contralateral tumor may develop, and thus avoid the risk of future adrenal failure. ${ }^{21-23}$

Before surgery, all patients with a secreting PC should be treated with alpha-blockers in order to avoid the risk of potentially fatal catecholamine storms ${ }^{24}$ : this treatment usually lasts for 2-4 weeks, and 
the patient needs to be carefully monitored before, during, and after surgery. Even if some authors ${ }^{25}$ questioned the use of alpha-blockers preoperatively when a mini-invasive approach is planned, pretreating hypertension seems so far the most reasonable approach. ${ }^{26,27}$

A mini-invasive approach is feasible but it should be performed preferably in tertiary centers with high volumes of oncologic cases and laparoscopic procedures in the pediatric population. ${ }^{24,25,28}$ This is justified in order to minimize the possible onset of severe intraoperative complications (such as severe bleeding) and to maximize the benefit of laparoscopic surgery. Moreover, the possible need of intensive postoperative monitoring should be taken into consideration.

The different localizations of PGL require a multidisciplinary discussion ${ }^{12,29}$ among different specialists who should always be involved on the basis of the tumor site and invasiveness (ear, nose, and throat surgeons; vascular surgeons; and interventional radiologists), with the aim to perform a complete resection, avoiding severe surgical sequelae. In two patients in our series, angiographic embolization was used to reduce the mass before the surgery in one case and in association with systemic therapy to treat an unresectable mass in another case. The use of alternatives to surgical excision (angiographic embolization, radiofrequency ablation, or cryoablation) has been mostly described for metastatic PC/PGL. ${ }^{30}$ A recent systematic review ${ }^{31}$ underlined how ablation techniques have been used in adults with different aims (palliative care, symptom control, or treatment of unresectable lesions, with or without other associated systemic/local therapies), while, in the pediatric age group, their application is still anecdotal. ${ }^{32,33}$

As reported before, ${ }^{34}$ the use of chemotherapy and its efficacy are difficult to determine, since patients who received medical treatment were inoperable or presenting with multiple relapses. Similarly, this is true for radiotherapy and radiometabolic therapy, even though some relapsed patients seemed to benefit from a multimodal approach. Thus, the most commonly used radiometabolic treatment is ${ }^{131}$ I-MIBG, and promising results seem to come from the use of ${ }^{177}$ Lu-DOTATATE. ${ }^{35-37}$ In our series, only two patients were eligible for ${ }^{177}$ Lu-DOTATATE, but the response has not yet been evaluated, since their treatment is ongoing.

The outcome in our series is apparently better than the previous reported experiences, especially as concerns patients affected by PC. ${ }^{2,34}$ PGLs seem to have a worse prognosis, and this may be due to late diagnosis, site and local invasiveness: since they arise from paraganglia, these tumors grow along major vessels, encasing them in some cases, making an $\mathrm{RO}$ resection difficult to be obtained (as similarly seen in childhood neuroblastoma surgery). This difficulty to obtain a complete surgical resection could be considered one main prognostic factor inthe PGL subgroup.

Some studies ${ }^{38,39}$ observed a significantly higher rate of relapse in patients with a germline mutation, but this observation was not confirmed by our findings. Despite 8 of 10 patients who experienced a relapsebeing carriers of a germline mutation, and an apparent difference in the cumulative risk curves, the analysis did not reachstatistical significance. This may be due to different reasons: low number of patients, heterogeneity in follow-up duration, different features of the two subgroups examined (PC and PGL), and the nature of the registry itself. In particular, absent or less prolonged follow-up of pediatric patients suffering from a familial PC/PGL and who may present with a relapse or a metachronous tumor later in life, have been suggested to explain this issue. ${ }^{38}$

However, several studies underlined the importance of careful follow-up especially in carriers of VHL and SDHD mutations because of their predisposition to develop recurrences or metachronous tumor. ${ }^{4,13,39,40}$ Reasonably, the subset of patients with a proven germline mutation should be followed for a longer time period and managed properly until adult care transition.

In conclusion, PC/PGL represents a group of neoplasms whose care raises several issues and strongly requires a multidisciplinary approach: the diagnostic process, treatment, and follow-up for children affected may represent a challenge for all the physicians involved. It is highly desirable that all pediatric patients affected may be referred to and treated in pediatric tertiary centers, where they can find all the necessary specialists and appropriate investigations. Moreover, as for other very rare tumors, it seems quite urgent to make registries go beyond national borders and create larger prospective international studies to achieve more information on epidemiology and a better knowledge of the clinical and genetic characteristics of these tumors.

\section{CONFLICT OF INTEREST}

The authors declare that there is no conflict of interest.

\section{ACKNOWLEDGEMENT}

The TREP project was partially supported by a grant from "Fondazione Giovanni Celeghin ONLUS," Padova.

\section{DATA AVAILABILITY STATEMENT}

The data that support the findings of this study are available on request from the corresponding author. The data are not publicly available due to privacy or ethical restrictions.

\section{ORCID}

Calogero Virgone (iD https://orcid.org/0000-0002-3651-9416

Alessandro Crocoli (iD) https://orcid.org/0000-0003-2157-4233

Alessandro Inserra (iD https://orcid.org/0000-0002-5663-8674

Paolo D'Angelo (iD https://orcid.org/0000-0002-4021-8472

Andrea Ferrari (iD https://orcid.org/0000-0002-4724-0517

Gianni Bisogno iD https://orcid.org/0000-0003-4462-5523

\section{REFERENCES}

1. Babic B, Patel D, Aufforth R, et al. Pediatric patients with pheochromocytoma and paraganglioma should have routine preoperative genetic testing for common susceptibility genes in addition to imaging to detect extra-adrenal and metastatic tumors. Surgery. 2017;161(1):220-227. 
2. Ciftci AO, Tanyel FC, Senocak ME, Büyükpamukçu N. Pheochromocytoma in children. J Pediatr Surg. 2001;36(3):447-452.

3. Chang CA, Pattison DA, Tothill RW, et al. (68)Ga-DOTATATE and (18)FFDG PET/CT in paraganglioma and pheochromocytoma: utility, patterns and heterogeneity. Cancer Imag. 2016;16(1):22.

4. Bausch B, Wellner $U$, Bausch $D$, et al. Long-term prognosis of patients with pediatric pheochromocytoma. Endocr Relat Cancer. 2013;21(1):17-25.

5. Neumann HP, Bausch B, McWhinney SR, et al. Germ-line mutations in nonsyndromic pheochromocytoma. N Engl J Med. 2002;346:14591466.

6. Neumann HP, Pawlu C, Peczkowska M, et al. Distinct clinical features of paraganglioma syndromes associated with SDHB and SDHD gene mutations. JAMA. 2004;292:943-951.

7. Bayley JP, Kunst HP, Cascon A, et al. AF2 mutations in familial and sporadic paraganglioma and phaeochromocytoma. Lancet Oncol. 2010;11:366-372.

8. Burnichon N, Briere JJ, Libe R, et al. SDHA is a tumor suppressor gene causing paraganglioma. Hum Mol Gen. 2010;19:3011-3020.

9. Qin Y, Yao L, King EE, et al. Germline mutations in TMEM127 confer susceptibility to pheochromocytoma. Nat Genet. 2010;42:229-233.

10. Comino-Mendez I, Gracia-Aznarez FJ, Schiavi F, et al. Exome sequencing identifies MAX mutations as a cause of hereditary pheochromocytoma. Nat Genet. 2011;43:663-667.

11. Mannelli M, Ercolino T, Giache V, Simi L, Cirami C, Parenti G. Genetic screening for pheochromocytoma: should SDHC gene analysis be included. J Med Genet. 2007;44:586-587.

12. Waguespack SG, Rich T, Grubbs E, et al. A current review of the etiology, diagnosis, and treatment of pediatric pheochromocytoma and paraganglioma. J Clin Endocrinol Metab. 2010;95(5):2023-2037.

13. Rednam SP, Erez A, Druker H, et al. von Hippel-Lindau and hereditary pheochromocytoma/paraganglioma syndromes: clinical features, genetics, and surveillance recommendations in childhood. Clin Cancer Res. 2017;23(12):e68-e75.

14. Ferrari A, Bisogno $G$, De Salvo $G L$, et al. The challenge of very rare tumors in childhood: the Italian TREP Project. Eur J Cancer. 2007; 43:654.

15. Pastore G, De Salvo GL, Bisogno G, et al. Evaluating access to pediatric cancer care centers of children and adolescents with rare tumors in Italy: the TREP project. Pediatr Blood Cancer. 2009;53:152.

16. Sait S, Pandit-Taskar N, Modak S. Failure of MIBG scan to detect metastases in SDHB-mutated pediatric metastatic pheochromocytoma. Pediatr Blood Cancer. 2017;64(11).

17. Hermsen MA, Sevilla MA, Llorente JL, et al. Relevance of germline mutation screening in both familial and sporadic head and neck paraganglioma for early diagnosis and clinical management. Cell Oncol. 2010;32:275-283.

18. Barontini M, Levin G, Sanso G. Characteristics of pheochromocytoma in a 4- to 20-year-old population. Ann N Y Acad Sci. 2006;1073:30-37.

19. De Krijger RR, Petri BJ, Van Nederveen FH, et al. Frequent genetic changes in childhood pheochromocytomas. Ann N Y Acad Sci. 2006;1073:166-176.

20. Cascón A, Inglada-Pérez L, Comino-Méndez I, et al. Genetics of pheochromocytoma and paraganglioma in Spanish pediatric patients. Endocr Relat Cancer. 2013;20(3):L1-L6.

21. Volkin D, Yerram N, Ahmed F, et al. Partial adrenalectomy minimizes the need for long-term hormone replacement in pediatric patients with pheochromocytoma and von Hippel-Lindau syndrome. J Pediatr Surg. 2012;47(11):2077-2082.

22. Fallon SC, Feig D, Lopez ME, Brandt ML. The utility of cortical-sparing adrenalectomy in pheochromocytomas associated with genetic syndromes. J Pediatr Surg. 2013;48(6):1422-1425.

23. Gupta A, Agarwala S, Tandon N, et al. Pheochromocytoma management, outcomes and the role of cortical preservation. Indian J Pediatr. 2014;81(8):780-784.
24. Romero M, Kapur G, Baracco R, Valentini RP, Mattoo TK, Jain A. Treatment of hypertension in children with catecholamine-secreting tumors: a systematic approach. J Clin Hypertens. 2015;17(9):720-725.

25. Walz MK, lova LD, Deimel J, et al. Minimally invasive surgery (MIS) in children and adolescents with pheochromocytomas and retroperitoneal paragangliomas: experiences in 42 patients. World J Surg. 2018;42(4):1024-1030.

26. PDQ $®$ Pediatric Treatment Editorial Board. PDQ Childhood Pheochromocytoma and Paraganglioma Treatment. Bethesda, MD: National Cancer Institute.

27. Challis BG, Casey RT, Simpson HL, Gurnell M. Is there an optimal preoperative management strategy for phaeochromocytoma/paraganglioma. Clin Endocrinol. 2017;86(2):163-167.

28. Heloury Y, Muthucumaru M, Panabokke G, Cheng W, Kimber C, Leclair MD. Minimally invasive adrenalectomy in children. J Pediatr Surg. 2012;47(2):415-421.

29. Peycelon M, Audry G, Irtan S. Minimally invasive surgery in childhood cancer: a challenging future. Eur J Pediatr Surg. 2014;24(6):443-449.

30. Kohlenberg J, Welch B, Hamidi O, et al. Efficacy and safety of ablative therapy in the treatment of patients with metastatic pheochromocytoma and paraganglioma. Cancers. 2019;11(2):E195.

31. Gómez FM, Patel PA, Stuart S, Roebuck DJ. Systematic review of ablation techniques for the treatment of malignant or aggressive benign lesions in children. Pediatr Radiol. 2014;44(10):1281-1289.

32. Zambaiti E, Siles Hinojosa A, Montano $V$, et al. Interventional radiology-guided procedures in the treatment of pediatric solid tumors: a systematic review and meta-analysis from the group of young pediatric surgeons of Europe. Eur J Pediatr Surg. 2019. https://doi.org/10.1055/s-0039-1692655.

33. de Paula Miranda E, Lopes RI, Padovani GP, et al. Malignant paraganglioma in children treated with embolization prior to surgical excision. World J Surg Oncol. 2016;14(1):26.

34. Pham TH, Moir C, Thompson GB, et al. Pheochromocytoma and paraganglioma in children: a review of medical and surgical management at a tertiary care center. Pediatrics. 2006;118(3):1109-1117.

35. Vyakaranam AR, Crona J, Norlén O, et al. Favorable outcome in patients with pheochromocytoma and paraganglioma treated with ${ }^{177}$ Lu-DOTATATE. Cancers. 2019;11(7):909.

36. Goldsmith SJ. Targeted radionuclide therapy: a historical and personal review. Semin Nucl Med. 2020;50(1):87-97.

37. Jasim S, Jimenez C. Metastatic pheochromocytoma and paraganglioma: management of endocrine manifestations, surgery and ablative procedures, and systemic therapies. Best Pract Res Clin Endocrinol Metab. 2019. https://doi.org/10.1016/j.beem.2019.101354.

38. Pamporaki C, Hamplova B, Peitzsch M, et al. Characteristics of pediatric vs adult pheochromocytomas and paragangliomas. J Clin Endocrinol Metab. 2017;102(4):1122-1132.

39. Parasiliti-Caprino M, Lucatello B, Lopez C, et al. Predictors of recurrence of pheochromocytoma and paraganglioma: a multicenter study in Piedmont, Italy. Hypertens Res. 2019. https://doi.org/10.1038/s41440-019-0339-y.

40. Dhir M, Li W, Hogg ME, et al. Clinical predictors of malignancy in patients with pheochromocytoma and paraganglioma. Ann Surg Oncol. 2017;24(12):3624-3630.

How to cite this article: Virgone C, Andreetta M, Avanzini S, et al. Pheochromocytomas and paragangliomas in children: Data from the Italian Cooperative Study (TREP). Pediatr Blood Cancer. 2020;67:e28332. https://doi.org/10.1002/pbc.28332 